\title{
"ECHARNOS LA MANO". EXPERIENCIAS \\ ORGANIZATIVAS EN TORNO A LA SOSTENIBILIDAD \\ DE LA VIDA DE MUJERES TRABAJADORAS DEL \\ HOGAR MIGRANTES MAZATECAS EN COLONIAS \\ POPULARES DE PUEBLA (MÉXICO)
}

\section{"ECHARNOS LA MANO". ORGANIZATIONAL EXPERIENCES PERTAINING TO LIFE SUSTAINABILITY OF MIGRANT MAZATEC WOMEN WORKING IN DOMESTIC SETTINGS IN POPULAR NEIGHBORHOODS OF PUEBLA (MEXICO)}

Cristina Vera Vega y Magalí Marega*

Resumen: Analizamos las experiencias de organización colectiva en torno al trabajo para la sostenibilidad de la vida, de mujeres trabajadoras del hogar mazatecas migrantes internas a la ciudad de Puebla, México. Muchas de ellas comenzaron a "trabajar en casa" desde tempranas edades y, aunque esta labor ha sido su experiencia laboral más regular, también se dedicaron al comercio o la elaboración de artesanías, y de modo permanente, al trabajo no remunerado en sus propios hogares y comunidades.

Proponemos definir estas formas organizativas como politicidad doméstica, dinámica que trasciende los canales formales de expresión, y que se ancla en experiencias cotidianas de organización en torno a redes de reciprocidad, cooperación y cuidados, no

* Doctorandas en Antropología por el Centro de Investigaciones y Estudios Superiores en Antropología Social (CIESAS), Sede Ciudad de México. Becarias CLACSO-CONACYT. 
exentas de conflictos. Estas dinámicas tienen antecedentes directos en los entramados comunitarios construidos históricamente, que se actualizan de modos diversos al llegar a las grandes ciudades, y especialmente en contextos de crisis exacerbada como el abierto por la pandemia.

Palabras claves: trabajo del hogar; sostenibilidad de la vida; politicidad doméstica; mujeres migrantes internas; crisis

Abstract: We analyzed the experiences of collective organization surrounding work for the sustainability of life, of Mazatec women domestic workers who migrated internally to the city of Puebla, Mexico. Many of them began to "work at home" (i.e. house cleaning, cooking, caring for children) from an early age and, although this work has been their most regular work experience, they also engaged in commerce or handicraft making, and permanently, in unpaid work in their own homes and communities.

We propose to define these organizational forms as domestic politicity, a dynamic that transcends formal channels of expression and is anchored in daily experiences of organization around networks of reciprocity, cooperation and care, which are not exempt from conflicts. These dynamics have direct antecedents in the community networks built historically, which are updated in different ways when they reach the big cities, and especially in contexts of exacerbated crises such as the one caused by the pandemic.

Key words: Domestic work; Sustainability of life; Domestic politicity; Internal migrant women; Crises

\section{INTRODUCCIÓN}

En este artículo abordamos la organización colectiva de mujeres trabajadoras remuneradas del hogar mazatecas de San Lorenzo Cuaunecuiltitla-Oaxaca, migrantes a la ciudad de Puebla - la cuarta ciudad más poblada de México. Nos centramos en las prácticas y vínculos que se construyen en torno al trabajo de sostenimiento de la vida familiar y comunitaria, fenómenos que decidimos llamar politicidad doméstica. De manera permanente y aún más en contextos de radicalización de la crisis como la que está provocando el COVID-19, las organizaciones colectivas y comunitarias, en la mayoría de los casos construidas por mujeres, muchas de ellas migrantes, racializadas y jó- 
venes, tienden a profundizar sus vínculos y a sostener con más fuerza a sus miembros. Estas formas organizativas, no siempre son visibles, porque escapan a las lógicas tradicionales e institucionales de organizaciones formales, indígenas o sindicales. La politicidad doméstica, especialmente de mujeres trabajadoras, son los andamios invisibles que sostienen la vida en la cotidianidad y aún más en contextos de crisis. No buscamos idealizar las condiciones de desigualdad o las vulneraciones que estas mujeres han vivido de manera histórica, sino reconstruir una apuesta ético-política de visibilización y reconocimiento de estas formas de organización colectiva en torno al trabajo.

Las últimas décadas presentan una producción fértil sobre el debate acerca de la centralidad de la reproducción social y la sostenibilidad de la vida, principalmente desde los feminismos. Aquí planteamos un diálogo de diversas líneas de pensamiento referidas a las intersecciones entre trabajo, género, colonialidad y despojos (Quijano, 2000; Nahuelpán, 2013; Chirix, 2012; Federici, 2016; Varela 2017; Navarro, 2019) recuperamos los aportes, centralmente desde los feminismos, de análisis situados sobre trabajo remunerado y no remunerado en los hogares, considerando diversas aproximaciones y abordajes, entre ellos, el trabajo doméstico y cuidados transnacionales, migraciones campo ciudad, dinámica organizativa y sindical, economía popular, trabajo afectivo (Young, 1989; Cumes, 2014; Carrasco, 2017; Durin 2017; Gago et al, 2018; Vega et al., 2018; Vega, Marega y Saltzmann, 2019). El debate sobre las formas de producir lo común, es otro gran eje en este trabajo y posee una relación de intimidad con la discusión sobre la politicidad (Gutiérrez y Salazar, 2015; Gutiérrez, 2017; Quiroga y Gago 2019; Tzul, 2020).

Las preguntas que transversalizan el interés analítico del artículo son las siguientes: ¿Qué formas adquiere la construcción de vínculos para la sostenibilidad de la vida y cómo se organiza la vida cotidiana en los barrios populares de Puebla para garantizar la reproducción social? ¿Qué potencialidades políticas abren estas dinámicas en contextos de profundización de la crisis? ¿Cómo operan las posicionalidades socio históricas y políticas de las mujeres migrantes trabajadoras domésticas en la construcción de espacios y temporalidades específicas? La principal hipótesis refiere a que las mujeres trabajadoras del hogar migrantes tienen modos específicos de dar forma a lo social, que, a partir de experiencias anfibias, atraviesan y configuran diversas territorialidades y temporalidades. En este devenir, operan procesos contradictorios y en disputa permanente 
para la sostenibilidad de la vida, que se sustentan en la conformación de redes y vínculos, con prácticas y tradiciones que se vinculan con formas de organizar lo social en sus comunidades de origen y que se actualizan en las ciudades de destino, enfrentando, adaptando y reconfigurando prácticas de apoyo y cooperación, y en ciertas ocasiones, incrementando las desigualdades y violencias.

Estas reflexiones se basan en una investigación etnográfica desarrollada entre noviembre de 2016 y agosto de 2020. El trabajo de campo consistió en una estancia durante 8 meses en la colonia popular Nueva San Salvador en Puebla y visitas cortas a la sierra mazateca en Oaxaca, México. También colaboramos durante 7 meses en una colecta para apoyar a trabajadoras del hogar mazatecas que se quedaron sin trabajo como consecuencia de la pandemia. Realizamos entrevistas a treinta mujeres mazatecas, de 4 generaciones distintas, oriundas de la sierra oaxaqueña, al sur de México, que migraron desde niñas a la ciudad de Puebla para realizar trabajo del hogar en casa de terceros - lo que popularmente se conoce como trabajo en casa.

Estructuramos estas reflexiones presentando en primer lugar la perspectiva teórica que guía esta investigación. Posteriormente, analizamos los procesos de despojo en el lugar de origen de estas mujeres en la zona mazateca de México, la conformación de redes de paisanaje y parentesco y la relevancia para y del trabajo de las mujeres en tales procesos. Seguidamente, presentamos las formas de organización en torno al trabajo en los barrios populares de la ciudad de Puebla, espacio al que llegan estas mujeres y colaboran en su conformación. En ambos acápites desarrollamos algunos de los elementos que configuran una politicidad doméstica que trasciende territorialidades y temporalidades. Por último, ponemos de relieve los modos en que se activa la politicidad doméstica en momentos de crisis exacerbadas como la que vivimos por el COVID-19.

\section{REPRODUCCIÓN, CUIDADOS, SOSTENIBILIDAD DE LA VIDA Y POLITICIDAD DOMÉSTICA}

Partimos de la definición de que el trabajo es toda actividad que media las relaciones sociales y el intercambio con la naturaleza para la reproducción de la vida. Por lo tanto, en términos genéricos es una actividad que funda humanidad, que permite la producción de sentidos y constituye al sujeto. Sin embargo, en su actual realización 
histórica, es preciso entenderlo como producto y productor de las relaciones de desigualdad y explotación, que se despliega en configuraciones racistas, patriarcales y colonial — capitalistas. En este sentido, retomamos los postulados de la antropología económica y la economía feminista que tiende a considerar al trabajo más allá de las relaciones laborales de dependencia o de empleo, para expandirlas hasta los procesos de reproducción material de una sociedad, ámbito en el que se ejerce el trabajo del hogar.

Las actividades desarrolladas por niñas y mujeres en el ámbito doméstico han sido consideradas como no trabajo por no pertenecer directamente a las relaciones de mercado (Dalla Costa y James 1972; Federici 2016). Esa estructuración históricamente jerarquizada y desigual produce sentidos y valorizaciones sobre el trabajo y las personas que lo realizan, así las tareas del hogar son realizadas por cuerpos empobrecidos, feminizados y racializados, lo que pone en evidencia la desigual distribución en la organización social de los cuidados y que explica una parte importante de las desigualdades actuales. En esa división desigual, niñas, adolescentes y mujeres adquieren responsabilidades de cuidado, alimentación y quehaceres domésticos, tanto en sus hogares como en el de terceros. En tal sentido, Cristina Vega, Raquel Martínez y Miriam Paredes (2019), sostienen que "la reproducción contribuye a ampliar la mirada y enfocar conjuntos y procesos sociales bastos, los arreglos de cuidado nos ayudan a contemplar tareas y actores concretos, situados y en relación" (p. 22). Las autoras nos solicitan ampliar el entendimiento sobre los cuidados para pensar su importancia para la sostenibilidad de la vida, en la que se incluye no solo el cuidado de las personas, sino que se relaciona con el cuidado del entorno. Este aporte no solo nos permitirá analizar la complejidad histórica en el que se cimienta el trabajo del hogar, sino su importancia esencial para el sostenimiento de la vida y las sociedades. En tal sentido, constituye una contribución no sólo en términos conceptuales, sino también en términos políticos.

Centrarnos en la sostenibilidad de la vida provoca un corrimiento conceptual y plantea la necesidad de ampliar la noción de politicidad. En tal sentido, seguimos a Raquel Gutiérrez y Huáscar Salazar quienes incorporan la producción de lo común, es decir, esa "amplia constelación de prácticas y esfuerzos que se afirman en la reproducción de la vida social a través de la generación y regeneración de vínculos concretos que garantizan y amplían las posibilidades de existencia colectiva - y por tanto individual — en tanto producen una trama social siempre 
susceptible de renovación, de autoregeneración” (p. 21). Según Gutiérrez, entender la centralidad de las tareas de reproducción de la vida y la organización colectiva y comunitaria que hay detrás de estas tareas, nos permite ampliar la idea de politicidad en clave femenina.

La reproducción de la vida material ha sido el centro de atención tradicional de la actividad femenina no exclusiva pero sí crucial... La política desplegada desde ahí, desde esos ámbitos múltiples y variados de asociación para la satisfacción de necesidades vitales, es una forma legítima de la política que puede denominarse, para distinguirla de otras formas políticas, política en femenino (Gutiérrez, 2017, p. 79)

Desde nuestra perspectiva retomamos el sentido propuesto por Gutiérrez, sin embargo, proponemos una mirada que permita bucear en los pliegues de la política en femenino, evitando la homogeneización de los cuerpos feminizados. Sostenemos que los modos que las mujeres se dan históricamente para organizar lo social, devienen de posicionalidades históricas y políticas, marcadas por interseccionalidades como la raza, etnia, género, edad, procedencia, entre otras. En este sentido, preferimos nombrarlas como formas de politicidad doméstica, es decir, los modos de dar forma a lo social, a través de la creación de "espacios, infraestructuras y redes capaces de resolver necesidades y producir bienestar colectivo" (Quiroga y Gago 2019, p. 80). Abordar lo doméstico "en términos etimológicos - domus, voz latina que refiere no solo a casa sino también a la idea de dominación del esclavo por parte del amo" (Durin, 2017, p. 21) - supone considerar justamente, las relaciones de dominación, explotación y opresión configuradas en contextos coloniales, al tiempo que plantear la politicidad en tales espacios (hogar, vecindad, comunidad, etc.) como formas de construir en colectivo las condiciones para una vida digna. Esta formación cuestiona, por lo tanto, la misma distinción entre público y privado y pone el foco en las experiencias complejas que se entrecruzan con diferentes modalidades de cooperación, reciprocidad y cuidados, que tienen un profundo anclaje histórico de conflictos y prácticas de dominación, "en negociación y en los intersticios del capital” (Gago et al., 2018, p. 20).

Considerar el trabajo para la sostenibilidad de la vida, y entre ellos el trabajo del hogar - y las experiencias de estas mujeres-, como históricamente situado, supone contemplar las violencias históricas que lo han estructurado y que forman parte de las lógicas 
que permiten el funcionamiento del capitalismo colonial/moderno y eurocentrado que consolidó un nuevo patrón, llamado por Aníbal Quijano (2000), como colonialidad del poder, cuyas características se encuentran vigente hasta nuestros días. Se puede afirmar que múltiples despojos y violencias son la condición sine qua non del capitalismo colonial, que desde su instauración consolidó formas de control y explotación del trabajo, clasificación social de la población mundial sobre la idea de raza, la degradación y control de los cuerpos de las mujeres, así como la propiedad privada, el mercado y la acumulación como fines últimos. Al centrar la violencia y el despojo como constitutivos de nuestras realidades, buscamos reflexionar sobre el modo en que estos procesos están conectados y generan un continuum de violencias (Varela, 2017), que van desde procesos de expulsión y migración forzada de grupos, hasta violencias que se viven en los cuerpos y que son en muchos casos interiorizados a través de procesos de tutelaje y disciplinamiento (Nahuelpán, 2013; Chirix y Emma 2012). En este sentido, podríamos hablar de despojos múltiples (Navarro 2019), que tienen efectos ecosistémicos, económicos, políticos y subjetivo-culturales sobre el tejido de la vida.

\section{DESPOJOS MÚLTIPLES Y CRISIS PERMANENTE}

San Lorenzo Cuaunecuiltitla, municipio libre del Estado de Oaxaca, es la zona más alta de la Sierra Mazateca mexicana y colinda con los Estados de Veracruz y Puebla. La movilidad territorial de hombres y mujeres indígenas mazatecas de diferentes edades para el trabajo agrícola, asalariado e informal ha sido una constante de la conformación de la mazateca oaxaqueña. Esta expulsión comenzó a inicios del siglo XIX y ha continuado con intensidades diversas producto de las transformaciones regionales generadas por las sucesivas crisis del sistema capitalista que han tenido impactos diferenciados en la ruralidad mexicana. Una de esas crisis fue la que se vivió a finales de los años sesenta del siglo XX con la caída en el mercado mundial de los precios de las materias primas (como el café, producción económica primordial en la sierra mazateca), lo que desencadenó un ciclo de migración de niñas y jóvenes a medianas y grandes ciudades.

Lupita, de 56 años y actual trabajadora del hogar, trabajó durante su niñez con sus abuelos, padres, tías, 4 hermanos y 5 hermanas en los ranchos cafetaleros ubicados a lo largo de la sierra mazateca. 
Recuerda que acompañaba a su abuela o hermanos mayores a trabajar en pequeños ranchos que eran administrados por mazatecos. En las épocas de corte se contrataban entre 20 y 25 personas incluyendo a niñas y niños.

Todos los días íbamos caminando. A las 4 de la mañana nos paraba mi mamá y como a las 5 y media llegábamos y nos llevaban a cortar café en camioneta. Ahí nos bajábamos en un voladero (peñasco o precipicio) donde se cortaba el café, bien feo. Teníamos que agarrar las matas de café y amarrarlo y para estar cortando el café, no parábamos a comer. A las 4 de la tarde venían por nosotros, llegábamos al pueblo a las 7 pm. (Lupita G., trabajadora del hogar, 2018).

El trabajo en los ranchos cafetaleros fue una opción en la que mujeres mazatecas de la edad de Lupita se emplearon por poco tiempo. La producción cafetalera pronto dejó de ser la salida laboral de los habitantes de San Lorenzo Cuaunecuiltitla. Lupita y Federico, su compañero, repasan esa experiencia: "Hace 50 años se cayó el café, la gente prefería que se pudra antes que seguir trabajando. El precio del café llegó hasta dos pesos el kilo... La gente comenzó a irse a la ciudad" (Federico R., contratista, 2020). Sumado a la caída internacional de los precios del café, a nivel nacional intervino una política basada en el incentivo a la industrialización en detrimento de la producción agropecuaria (Patiño, 2004), que generó desabastecimiento en las regiones campesinas y agrícolas. En la Sierra Mazateca, el acceso limitado de las familias campesinas e indígenas a la tierra y la progresiva falta de alimentos catalizaron la migración de la población local en búsqueda de fuentes de empleo.

En el caso de las mujeres, otra de las motivaciones centrales para migrar estaba ligada a las formas de herencia patrilineal de la tierra, que impidió que accedan al principal recurso para garantizar las condiciones de existencia. Las mujeres entrevistadas en esta investigación mencionaron que todavía los hombres reciben los terrenos, porque tradicionalmente se piensa que son los más aptos para el trabajo. Además, la institución del matrimonio es utilizada como elemento que legitima esa desigualdad, al sostener que las mujeres, cuando se casan, pierden el derecho a heredar porque se las entrega a la familia de su esposo. De allí que un dicho popular en San Lorenzo proclame que "una mujer que sale de su casa no debe mandar terreno". En este caso las herencias han sido mecanismos para controlar las decisiones 
de las mujeres. Como menciona Ana María Morales (2019), "las mujeres no tienen derecho a la tierra y pierden su autonomía al depender de una relación familiar o marital para alcanzarla" (p. 87).

En esta vía podemos afirmar que las más perjudicadas de estos procesos de transición fueron las mujeres y los niños. Por un lado, su trabajo no era valorado sino considerado como una extensión del trabajo de los hombres (Federici, 2016), y por otro, debieron vivir estos procesos de expulsión desprotegidas, fruto de las condiciones coloniales y patriarcales que se reproducen, con cambios, en su lugar de origen, como se demuestra con la herencia de la tierra.

Las mujeres debieron enfrentar procesos de discriminación y exclusión también en el mercado laboral urbano, asistiendo a un quiebre de los lazos sociales con sus comunidades de origen. La vía más directa de incorporación de las mujeres fue el trabajo doméstico y el trabajo autónomo desprotegido (Vega, Marega y Saltzmann 2019, p. 554). A la par de la consolidación de esta transición económica, cuya cara más visible fue la creación de una nueva masa de trabajadores libres, continuaron ejecutándose formas de servidumbre doméstica colonial, que despojaron a miles de mujeres de sus hogares y su mundo, para colocarlos bajo el servicio de diferentes familias. Para Aníbal Quijano (2000), estos procesos de despojo también operaron bajo una lógica racial del trabajo, en los que hombres y mujeres con características sociales construidas como "inferiorizantes" se insertaron en ciertos tipos de trabajo que han sido construidos históricamente como subordinados.
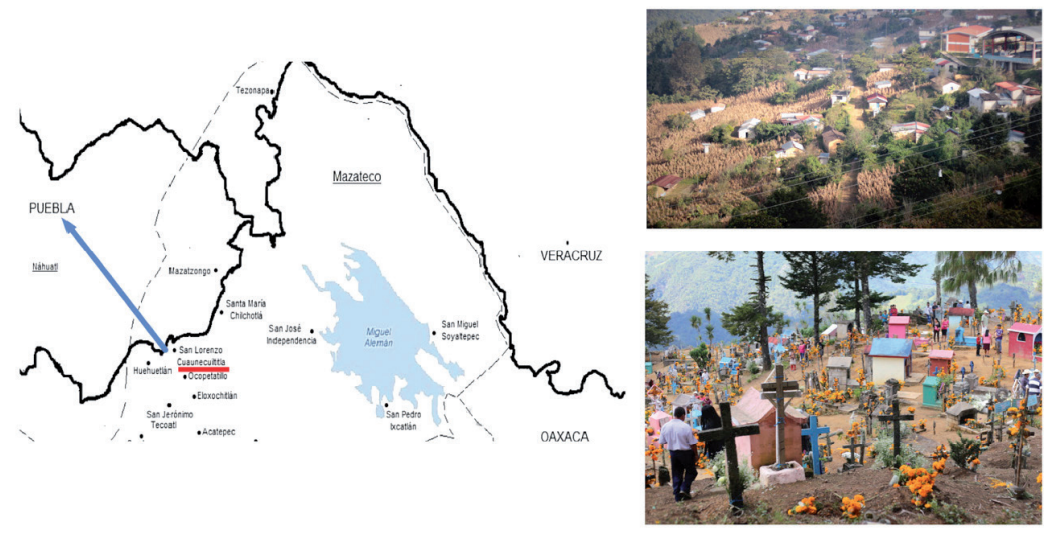

Municipio San Lorenzo Cuaunecuiltitla. Oaxaca 
En 1960, en el contexto de industrialización, Puebla, lugar de destino de las mujeres mazatecas, pasó a ser la tercera ciudad más importante en crecimiento industrial de México (Patiño, 2004). En esa década la (empresa automotriz) Volkswagen abandonó la Ciudad de México y se instaló en Puebla. También se construyó el parque industrial Quetzalcóatl y se fortaleció la industria textil, de larga duración en la generación de empleos. El crecimiento industrial significó la consolidación de la ciudad y de una clase media urbana que requirió una serie de servicios, entre ellos el "trabajo en casa". De parte del grupo empleador, también operó una división sexual del trabajo. Generalmente, los hombres que eran vistos como los jefes de hogar se emplearon como ingenieros o trabajadores en los nuevos empleos que generaron las industrias automotrices, textiles y como comerciantes. Por su parte, la mayoría de mujeres empleadoras de clase media urbana comenzaron a insertarse al mercado formal, como profesoras y secretarias. Esta condición generó la demanda de fuerza de trabajo feminizada para el trabajo doméstico lo que evidenció, por un lado, la conformación de un mercado laboral fuertemente estructurado en torno a jerarquización de clase, género y étnico-racial, y por otro, la desigual distribución en la organización social de los cuidados y que explica una parte importante de las desigualdades actuales. Los procesos de consolidación de ciudades como Puebla adquirieron un carácter dispar que trajo consigo oportunidades de empleo a mujeres en "trabajos de servicios de cuello blanco", mientras se despojó a niñas y niños de sus hogares, quienes se incorporaron a la masa de trabajadores de las ciudades y fueron colocadas bajo el servicio de diferentes familias.

Las niñas y jóvenes mazatecas llegaban a Puebla a la casa de sus paisanas o familiares hasta que les conseguían un trabajo. Una vez que cerraban el trato con los "patrones", las recién llegadas eran colocadas de modo permanente, bajo la modalidad "de planta", es decir, que residían en las casas que iban a trabajar. A finales de la década de los setenta Lupita y Obdulia, de 13 y 11 años respectivamente, en ese entonces, ya vivían en la casa de sus empleadores. La empleadora de Lupita era una mujer joven que acababa de "aliviarse" Lupita ya tenía algo de experiencia en el trabajo debido a que a sus 9 años había vivido en dos ciudades medianas, trabajando en el desvene de chiles y como recamarera. Al llegar a Puebla, relata que la

1 Expresión utilizada para designar a que recién había tenido su parto. 
comunicación con las familias empleadoras no fue difícil porque era bilingüe, castellano y mazateco.

Para Obdulia el proceso de adaptación fue más difícil. A pesar de haber vivido un tiempo con su hermano Antonio, la casa de sus "patrones era muy diferente" a su lugar de origen y como estuvo poco tiempo allí, no aprendió a hablar castellano.

Cuando salía el agua de la regadera me espanté y me salí. Yo me bañaba en el río, por eso me espanté con el agua. Luego me llevaron lejos para que no me saliera, hasta México (ciudad capital del país) y ahí tenía que resignarme, lloraba mucho. (Obdulia A., ex trabajadora del hogar, 2019).

Obdulia y Lupita manifestaron sentir mucha tristeza y espanto al llegar a los hogares trabajadores. En el caso de Obdulia, el temor se materializó en las diferencias infraestructurales entre la ciudad y el campo, cuando menciona el susto de estar por primera vez bañándose en una ducha y no en el río, como era su costumbre. Otro de los sentires que frecuentemente mencionaron las entrevistadas ha sido la resignación o "el aguantarse". Con el correr del tiempo y al adquirir algunas herramientas que le otorgaban confianza, como entender la lengua de la familia receptora, ellas coinciden en que comenzaron a insertarse progresivamente en la lógica del trabajo, aún con miedos y frustraciones. Obdulia recordaba cómo, de niña, en uno de sus trabajos tuvo que cuidar a un bebé sin ninguna experiencia. "Ahora me pongo a pensar cómo era posible que la mamá me lo confiara ‘Ahí está la bañera!’. Me daba mañas para bañarlo ¿y si se me cae?”, exclama Obdulia.

En este sentido, se da por sentado que las recién llegadas tienen conocimiento sobre las labores de cuidado, presunción que puede deberse a los estereotipos que se construyen alrededor de los cuerpos de niñas, jóvenes y mujeres indígenas que llegan de contextos rurales a trabajar a la ciudad. Desde el inicio de la relación se rompe el mito de que las mujeres tenemos interiorizadas las tareas de cuidado. Lo que sí se demuestra es que el trabajo en casa, remunerado o no remunerado, al igual que el resto de trabajos, necesita aprendizaje y capacitación, experiencia que se va dando a través de la puesta en práctica del propio oficio, transmitido, con frecuencia, por las mismas empleadoras.

En el caso de Obdulia y de muchas otras mujeres migrantes, la capacitación no solo se vincula con el oficio sino también con el 
aprendizaje del idioma y de lo que se concibe como enseñanzas civilizatorias. Obdulia menciona:

Me enseñaron a hablar, a comer, a bañarme. Me enseñaron cómo se agarraba la taza, a cerrar la boca, a agarrar los cubiertos, a hablar, a cuidar a los niños. Íbamos a restaurantes lujosos, me enseñaron cómo comer, cómo caminar (Obdulia A., ex trabajadora del hogar, 2019).

Con el testimonio de Obdulia podemos adentrarnos en los pliegues coloniales de la configuración del trabajo del hogar como actividad civilizatoria (Ramón, 2012; Vera y Vega, 2020). Según Aura Cumes (2014), "para el imaginario social la vida de los indígenas y de los pobres debe ser conducida por el camino del desarrollo y la civilización. El trabajo en casa es una forma de civilizar a las trabajadoras por parte de sus empleadores" (p. 206). Este sentido es compartido por Obdulia, quien considera que, el trabajo en casa, permitió a las mujeres que llegaban del pueblo "civilizarse". "Gracias a Dios se fueron civilizando las muchachas, les fue bien, muchas mujeres se quedaron con personas que tenían dinero, algunas son guapas, se civilizaron". Como demuestra el testimonio de Obdulia, la misión civilizatoria del trabajo doméstico se relaciona con el aprendizaje de normas de higiene, modos de usar el cuerpo y de comunicarse. A la vez, este proyecto civilizatorio se vinculaba con el estatus socioeconómico de la familia empleadora. No debemos olvidar que desde épocas coloniales el trabajo doméstico fue concebido como una forma de civilizar a las poblaciones indígenas y esclavizadas. Estas acciones eran consideradas como "formación de los subalternos en oficios manuales y en las nuevas costumbres coloniales (la idea de "aprendices", "ayudantes" o "niñeras"); era necesaria para que asuman trabajos complementarios, atender a los niños o jugar con ellos; era parte de la expectativa por vincularlas de por vida como servidoras leales de la casa" (Ramón, 2017, p. 17). También, contar con sirvientes domésticos se volvió símbolo de estatus, ya que subrayaba prestigio, al representar los diversos grupos en el seno de la familia.

La pretendida misión civilizatoria supuso un nuevo tipo de despojo de vínculos, saberes tradicionales e identidades, al mismo tiempo que fue valorado por ellas y sus familias como posibilidad de enfrentar las restricciones que el contexto de expoliación en sus zonas de origen les imponía, tales como la falta de acceso a la educación 
y servicios básicos. Estas concepciones hacen que las trabajadoras vean como ignorante o atrasado el contexto de donde vienen, lo que crea sentimientos de superioridad e inferioridad que tiene su correlato en la legitimidad de la autoridad de los empleadores.

Para que el carácter civilizatorio del trabajo del hogar sea visto como gestos de benevolencia, incluso de amor, y no como responsabilidades laborales, se hace uso de lo que Grace Young (1987) ha catalogado como el "mito de ser como una hija". Ficción con la que se sostiene las condiciones de explotación de este tipo específico de trabajo y que es parte de otras ficciones que se han diseñado para crear estructuras de sentimiento desiguales para reproducir prácticas de subordinación y privilegio (Berg y Ramos, 2017).

Al consultarle a Lupita cómo era la relación con su empleadora cuenta "ella me veía como empleada y yo como la patrona", aunque admite "le guardo mucho cariño porque fue Blanquita quien me enseñó a hacer el quehacer, me enseñó cómo barrer, cómo planchar, cómo lavar los platos, cómo comer". Lo que motiva el cariño de Lupita por su empleadora es el contacto y la enseñanza, "la señora o empleadora es la puerta de entrada a los brazos paternalistas de la familia" (Young, 1987, p. 368). En el caso de la empleadora, las motivaciones de la cercanía se construyen también por la enseñanza, que se convierte en una actividad que traerá beneficios para esta última, ya que después de algún tiempo podrá delegar a la niña o joven sus responsabilidades. Debemos recordar que la reproducción y el cuidado también son sectores altamente estratificados y aunque a diario estas mujeres están unidas por el deber de servir a la familia, es el trabajo de la trabajadora doméstica el que libera a la señora de las laboriosas tareas de cocinar, limpiar, lavar y planchar (Brites, 2007). Como menciona Esther Young el lenguaje de la familia al constituirse en apariencia como inclusivo, justo y con una división "natural" del trabajo y del poder basada entre otras categorías como la edad, y en el caso de las trabajadoras por su procedencia étnica y de clase, "sirven para estructurar una relación de desigualdad, de explotación poderosamente legitimada por la iglesia y el estado" (Young, 1987, p. 365)

El vínculo con las y los empleadores también opera, en ciertas ocasiones, como un mecanismo generador de redes a través de las cuales se despliegan transacciones, que generalmente suelen ser asimétricas. Lupita no ha dejado de visitar la casa de su primera empleadora ya que se siente agradecida porque "eran buenas 
personas", mientras que Obdulia decidió usar los nombres de sus empleadoras en sus hijas como forma de gratitud. Para Cuéllar "la reciprocidad se vuelve problemática cuando se trata de relaciones desiguales, en las que una de las partes detenta poder sobre la otra. En el servicio doméstico puede servir para que acuerdos laborales poco justos se acepten y se cuestionen poco o nada las condiciones laborales" (Cuéllar, 2020, p. 274). Sin embargo, además del agradecimiento, Lupita reconoció que "no tenía horario, me paraba a las seis y me dormía a la una de la mañana después de bañarme y terminar de planchar". Al no contar con lineamientos claros desde el Estado, cuestiones laborales que en trabajos formales desde el principio están pactados, como salarios, prestaciones y vacaciones, son vistos como actos personales de bondad. Así, los hogares empleadores se constituyen como lugar "conocido" o "propio" bajo el que se concentran diversas formas de control y solidaridad.

Como mencionamos, Lupita y Obdulia fueron niñas y jóvenes que llegaron a trabajar en hogares de la ciudad de Puebla durante la década de los setenta. Sin embargo, la crisis de la deuda externa mexicana de 1982 marcó el inicio de cambios estructurales y ajustes económicos promulgados por organismos internacionales como el FMI y el Banco Mundial (Velázquez, 2012), que ocasionó nuevas condiciones de precarización de las condiciones de vida de la clase trabajadora. La expulsión agraria, como forma de migración forzada, se conecta con las violencias que estas mujeres experimentaron en el trabajo en casa. En este sentido, hablamos de despojos múltiples (Navarro, 2019). No es tan sólo que la "acumulación pueda producirse como «acumulación por desposesión», como en la formulación de David Harvey (2006); es también el despojo del tiempo de vida (es decir, la explotación laboral), operada por el capital mediante sus sistémicos ciclos de retroalimentación" (Navarro, 2019, p. 15). Esto se evidencia con fuerza en la vida de las mujeres mazatecas. Desde la crisis agraria que las llevó a salir de su pueblo, hasta las crisis de desempleo en las ciudades, sus vidas han estado marcadas por crisis continuas. Estos ciclos de crisis, explotación y despojo se actualizan con fuerza en el contexto actual de la pandemia por COVID-19 que profundiza, dramáticamente, conflictos económicos, raciales y sexuales, que se expresan con violencia sobre los cuerpos de las mujeres. En este marco es que se desarrollan las experiencias de organización de las mujeres en torno al trabajo que, como vemos, trasciende diversas territorialidades y tiempos. 

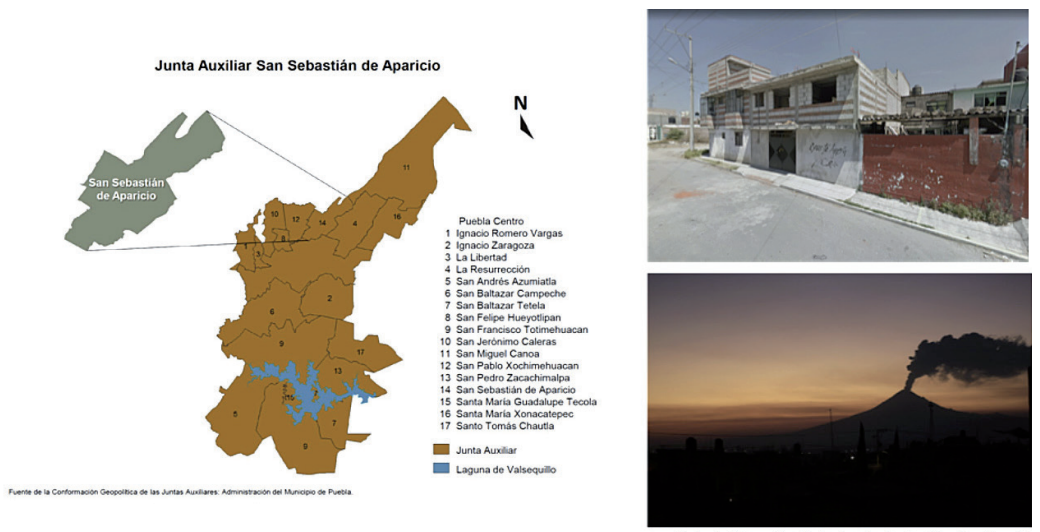

Colonia Nueva San Salvador. Junta Auxiliar San Aparici

\section{POLITICIDAD DOMÉSTICA EN TORNO AL TRABAJO}

Argumentamos que la especificidad que adquieren las prácticas de trabajo en torno a la sostenibilidad de la vida en este grupo de mujeres residentes en Puebla, configuran una politicidad doméstica, que se extiende por diversas territorialidades y se configura en múltiples horizontes temporales. El trabajo en casa, remunerado y no remunerado, se constituye como el eje vertebral de esta politicidad doméstica, que tiene como antecedente y piso común a las lógicas comunitarias de trabajo que, en este caso, desarrollan en las comunidades de la sierra niñas, niños, hombres y mujeres mazatecas. Para la población mazateca existen diferentes maneras de nombrar al trabajo comunal. Lupita menciona que el término mazateco Xo significa trabajar. Sin embargo, para el trabajo colectivo recíproco existe la denominación Xo'yo. Dice Lupita "Trabajamos entre todas. Un ejemplo, ayudo a envolver tamales y cuando yo tenga alguna reunión, la persona a la que ayudé va a venir a devolverme el día que yo ya fui, a eso se dice Xo'yo. Ahora hay más xo'yó, te ayudan y le ayudas" (Lupita G., trabajadora del hogar, 2020). Sin embargo, otra acepción para trabajo comunal es nyii. "Supongamos que tu quieras hacer una casa. Tienes los materiales, pero no tienes dinero, entonces la gente te va ayudar porque lo necesitas, y tú a cambio haces 
comida para agradecerles". Es decir, en este caso, el trabajo recibido no se devuelve con trabajo sino con productos. Otra expresión es Xobosan, que se conoce en castellano como faena y corresponde a los cargos laborales que tienen en el pueblo (San Lorenzo Cuaunecuiltitla) por y para pertenecer a la comunidad.

Es un requerimiento de la autoridad comunal, no se paga nada, se reúne todo el pueblo, limpian las calles, limpian el panteón y cuando se aproxima una fiesta limpian la cancha. En la ciudad también se dan faenas sobre todo en las escuelas, tenemos que limpiar el salón de nuestros hijos, si no asistimos tenemos que pagar (Lupita G., trabajadora del hogar, 2021).

Como bien menciona Gladyz Tzul (2020), "el trabajo comunal de las poblaciones indígenas no son esencias o identidades fijas, sino que es la capacidad que todos y todas tenemos para el sostenimiento de la vida comunal" (p. 389). En estos diversos sentidos sobre el trabajo se evidencia algunas de las tradiciones de vínculos y prácticas sobre las que se construyen las formas de politicidad doméstica en la gran ciudad a partir de redes de trabajo, paisanales, de madrinazgo y de compadrazgo que se han extendido a lo largo del tiempo. La politicidad doméstica en torno al trabajo se fue construyendo por tías y madrinas que realizaban comercio con la ciudad, fueron las encargadas de asistir, dar hospedaje y comida a las niñas y jóvenes que llegaron a la ciudad en busca de trabajo. Para Lupita.

Nosotros que somos migrantes, aquí cuando venimos a la ciudad no conocemos a nadie. A mí me trajo mi papá y luego paramos en la casa de una madrina de mi papá y tenía un cuartito chiquito, chiquito. Por eso era muy importante que nosotros estuviéramos en contacto con las personas que ya tenían casa, casi siempre rentada. Era un apoyo, imagínate nosotros no conocemos lo que se llama casa de huésped, no contábamos con nada solamente con los paisanos o familia. Nos ofrecían, aunque sea una taza de café, también nosotros traíamos algún producto del pueblo para entrar a la casa. (Lupita G., trabajadora del hogar, 2020).

Niñas y mujeres comenzaron a construir redes de trabajo y contención afectiva en Puebla, dinámica que tuvo como antecedente las estrategias de organización que desplegaban en su lugar de origen y que luego eran incorporadas con sus variaciones en la ciudad. Las madrinas se convirtieron en el vínculo entre las jóvenes trabajadoras 
migrantes y sus familias. Estas mujeres fueron las encargadas del cuidado de las pequeñas trabajadoras en la ciudad. Para Cristina Ohemichen (2013), los procesos migratorios exhiben la importancia de las estructuras de parentesco en el mundo contemporáneo. En este caso, las redes no solo garantizan el lugar donde llegar, sino que posibilitan el acceso a una fuente de empleo. Obdulia, por ejemplo, reconocía este encadenamiento de favores y confianza como un mecanismo dador de legitimidad y prestigio, el que los miembros de la red debían respetar.

Era por una red de solidaridad que iba ayudando a la gente, no creo que haya sido por dinero porque al final no le pagaban, le daban para su refresco, pero no era mucho. No era una cantidad, sino porque necesitaban, eso te da prestigio delante de la señora que ocupa muchachas porque tu eres la que acomoda la red. Es un poder simbólico, no monetario, porque eres tú quien les ubica. 'Pídele a la señora porque ella trae gente de confianza'. (Obdulia A., ex trabajadora del hogar, 2019).

"Acarrear", "recomendar" y luego "colocar" a una niña o joven recién llegada a Puebla, constituían actividades legitimadas y valoradas socialmente, apuntaladas luego por la elección del parentesco ritual, es decir, generalmente estas mujeres se convertían en madrinas o comadres de las recién llegadas. Este proceso de acompañamiento y colocación no se realizaba a cambio de un pago monetario, sino que se resarcía con poder simbólico a través de la consecución de prestigio y respeto, tanto con los paisanos del campo y la ciudad, así como con el grupo empleador. El madrinazgo se convirtió en ese vínculo que cobijó a las trabajadoras jóvenes.

Si bien este tipo de vínculo se puede caracterizar como una forma de relación horizontal y solidaria, basada en la estima y reciprocidad, también se generaron preferencias con las jóvenes más cercanas a las tías o madrinas. Aquellas "preferidas" por las madrinas eran llevadas a casas de empleadores con dinero. Las jóvenes trabajaban, únicamente, como recamareras o niñeras, ya que tenían a dos o tres compañeras más que se hacían cargo del trabajo en la cocina, el lavado de ropa, el quehacer de la casa, entre otras actividades.

Los fines de semana las casas de las madrinas se convertían en los puntos de reunión de las jóvenes trabajadoras. Para Lupita, las personas que las recibían eran las que se responsabilizaron de las niñas y jóvenes recién llegadas a la ciudad, también, se encargaron de activar 
las redes laborales para conseguirles empleo. Estas redes de trabajo han permitido contar con ofertas de empleo permanentes. Para Lupita

Si nosotros conocemos ya la ayudamos a colocar a la niña que traigan. 'Aquí traigo a mi niña para que trabaje', y ya nosotros que tenemos más tiempo acá, preguntamos que, si hay trabajo, y sino, ahí que se quede mientras la conseguimos trabajo para colocarla y ya así. Nosotros vamos y preguntamos con nuestras patronas o con alguien que hayamos estado, y a donde nosotros nos traten bien también, no les vamos a llevar donde nos trataban mal. Y si ya nos dice 'pues tráemela', la llevamos y ya se coloca ahí (Lupita G., trabajadora del hogar, 2021).

Más allá de las preferencias con algunas, o la selección de lugares donde "no las trataran mal", es importante mencionar aquí que, para mantener la confianza y la "membresía" en esas redes también se debía garantizar fidelidad en el trabajo, lo que muchas veces suponía disponibilidad horaria para jornadas extenuantes. Aún con experiencias heterogéneas, la valorización positiva de estas redes y su sostenimiento, se daba en un marco de abandono estatal en la garantía de las condiciones de reproducción y existencia. Ninguna de las mujeres mazatecas entrevistadas cuenta con seguridad social, por lo que se revalorizan las formas de auto-organización que suplen al Estado.

En la década de los ochenta y principios de los noventa, esta red de mujeres también permitió acceder a terrenos al norte de la ciudad de Puebla. Fue a través de la "plática" y el "consejo entre amigas, vecinas y parientes" que estas mujeres encontraron terrenos de cultivos que se lotizaban al norte de la ciudad de Puebla, en las colonias Roma y Nueva San Salvador. Acudir con lotizadores de confianza, y adquirir terrenos fuera de procesos fraudulentos fue lo que posibilitaron estos vínculos. Posteriormente, se sumaba el reclamo que se le hacía a la municipalidad para la construcción de infraestructura e instalación de servicios básicos. La compra de terrenos cercanos permitió construir procesos de vecindad con las redes familiares y de paisanaje, que al mismo tiempo les permitió la creación de espacios de cuidado comunitario de los niños ya nacidos en Puebla. Eso propició la confianza entre mujeres, especialmente las más jóvenes, que comenzaron a delegar el cuidado de sus hijos a sus comadres o familiares, creando cadenas de cuidado dentro de la ciudad.

Actualmente, estas redes se mantienen gracias al aporte de dones y contra dones de sus integrantes. Sus miembros organizan activida- 
des a lo largo del año. Las festividades no se viven de manera aislada, sino que constituyen un momento para afianzar lazos. Realizar una fiesta de grandes dimensiones no solo es una forma de demostrar estatus, sino de expresar agradecimiento a compadres y paisanos. Las festividades religiosas de bautizos, comuniones, confirmaciones, celebración de quince años, que suelen rondar entre los 200 y 300 invitados, es una forma de unir a paisanos y familiares. Las mujeres mazatecas son las encargadas de la preparación de la comida, generalmente platos típicos de su lugar de origen, como el tesmole de pollo, mole y otros platillos. En estas ocasiones se despliega una especie de compadrazgo festivo. Se eligen padrinos y madrinas del pastel, de las bebidas, del equipo de sonido, del video, que consiste en que el o la así nombrada, se haga responsable económicamente de esos gastos específicos. Los cargos y obligaciones van rotando en las siguientes festividades. Hay un intercambio transaccional entre bienes materiales y simbólicos, es decir, la devolución es el prestigio de quien hospeda y organiza la fiesta.

También el convite se vuelve una práctica que se activa en las festividades. Si la organizadora no tiene para pagar las bebidas en una fiesta, pide a una paisana o comadre que "le ponga a cambio". Las bebidas se devolverán cuando la persona que prestó realice una celebración. Después de preguntarle acerca de por qué invitaba a tanta gente en sus fiestas, Lupita contestó:

Los invito porque todos saben que yo hago fiesta, todo mundo me pregunta ' ¿ya viene la fiesta de su hija? Si quieres te ponemos esto y me apoyan, por eso es que también lo hago. Luego me dicen yo te pongo el pastel, yo te pongo el refresco, y luego tú me dices ya te pongo el video, luego me dicen yo te pongo las mesas, yo te pongo el adorno, yo te pongo los globos, así y cuando ella vuelve a hacer fiesta, regreso el favor (Lupita G., trabajadora del hogar, 2021).

Otra manera de organización se da a través de los préstamos y la redistribución. En conjunto se organizan con familiares, comadres y paisanos para ahorrar y obtener dinero para "salir de apuros". Las tandas ${ }^{2}$ como método de ahorro o compra colectiva, prioriza en el orden de entrega a la persona que tenga más necesidad. También las redes

2 Una tanda es una forma de ahorro. Consiste en un grupo de personas que toman turnos para recibir beneficios monetarios o materiales que se van acumulando cada semana, cada dos o cada mes y el organizador establece el tiempo que dura la tanda dependiendo de lo que se entregue. 
familiares envían dinero a sus miembros que viven en San Lorenzo como una forma de redistribución familiar. El pago de servicios básicos en conjunto, como la compra de pipas de agua — así llaman a la provisión de agua potable mediante camiones cisterna- cada dos semanas, o tequios - trabajo colectivo- para el arreglo de la calle es una manera de generar formas de organización ante la ausencia estatal.

Las prácticas de las mujeres han sido transformadoras y transgresoras de la economía del capital. Estas mujeres se organizan entre sí a través de redes vecinales y de parentesco para la obtención de trabajo, para el cuidado de hijos/as y adultos mayores y para elaborar estrategias de cuidados colectivos ante la violencia machista. Estas prácticas organizativas no solo constituyen formas de apoyo económico sino son modos de contención emocional, mediante los cuales se intenta subvertir las violencias estructurales imperantes y desafiar la opresión en múltiples formas, aunque con efectos diversos.

Como hemos visto, estas formas de politicidad han sido construidas a lo largo del tiempo, desde diferentes generaciones de mujeres mazatecas, lo que deja de lado que sean experiencias exclusivas de mujeres adultas. Asimismo, estas formas de organización están condicionadas por la experiencia migrante, laboral, racial, étnica, de clase, posicionalidades que hacen posible el desarrollo de estas formas de política. A pesar de los procesos de despojos múltiples que han marcado las experiencias vitales de estas mujeres que han dedicado toda su vida al trabajo del hogar, también permite entender la importancia esencial de este tipo de trabajo para el sostenimiento de la vida y las sociedades.

\section{MUJERES MAZATECAS}
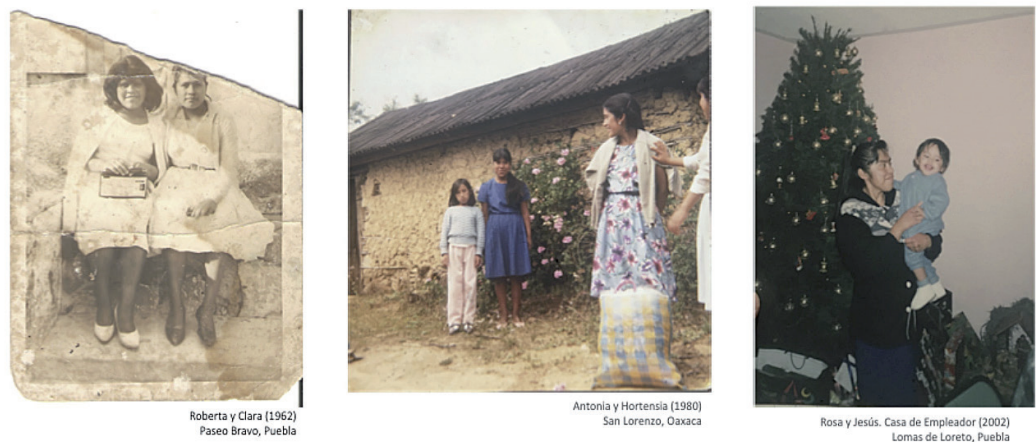

Lomas de Loreto, Pueb| 


\section{POLITICIDAD DOMÉSTICA DURANTE LA CRISIS PANDÉMICA}

La contingencia del COVID-19 comenzó a sentirse en México los primeros días de marzo de 2020 cuando la población entró en confinamiento. Un gran número de las y los trabajadores que se encontraban trabajando en empleos formales y que no pertenecían a sectores considerados esenciales, adoptaron la modalidad de teletrabajo, mientras que la población trabajadora informal, como el sector de las trabajadoras del hogar, se ha visto afectada de diversos modos. La crisis causada por el COVID ha visibilizado y agudizado las desigualdades estructurales en las que se cimienta el trabajo en casa y ha demostrado la vulnerabilidad y violencia a las que están expuestas las mujeres trabajadoras del hogar. Las consecuencias de la crisis han afectado tanto a las trabajadoras de planta como a las de "entrada por salida", como se les llama a aquellas que no residen en la casa empleadora.

Varias trabajadoras de planta, que aún conservan su empleo, comentaron que la carga de trabajo se ha intensificado desde que comenzó la crisis, han recibido amenazas de despido y han vulnerado sus derechos laborales de libre movilidad y de obligatoriedad de descanso. Del mismo modo, para las trabajadoras de entrada por salida la vulneración a sus derechos comenzó desde antes que se agudizara la crisis. Los riesgos de contraer COVID-19 en los largos trayectos desde sus hogares a los de sus empleadores, profundizaron prácticas violentas hacia las trabajadoras. En algunos casos, sus empleadores rociaban con sanitizantes varias veces por día a las mujeres, les solicitaban que no hablaran, a la mayoría le bajaron el salario, y a muchas las despidieron. A ello se le suma el escaso o nulo acceso a la seguridad social ya que se estima que "el $1 \%$ de las 2,5 millones de trabajadoras del hogar que hay en México está afiliada al Instituto Mexicano de Seguridad Social" (Arteta, 2021)3. Para Marcelina Bautista, Secretaria General del Sindicato Nacional de Trabajadoras del Hogar de México (SINACTRAHO), la contingencia vuelve a visi-

3 En julio de 2020 México ratificó el Convenio 189 de la OIT sobre el trabajo doméstico, fruto de una lucha histórica de las trabajadoras remuneradas del hogar organizadas en SINACTRAHO. Algunos informes (COPRED, 2021) señalan que aún son incipientes las reformas para adaptar la normativa nacional al Convenio, la ratificación no es suficientemente conocida por las trabajadoras y queda un gran desafío para el cumplimiento de tales derechos. 
bilizar las condiciones de desigualdad en las que históricamente se asentó el trabajo del hogar.

El perfil de empleadores actual ya no está compuesto sólo por personas mexicanas, sino que también emplean a mujeres mazatecas, algunos ciudadanos alemanes que llegan a trabajar a Puebla por períodos de varios años, en empresas como Audi y Volkswagen. Aunque los salarios diarios son mejores, que alcanzan entre 400 a $500^{4}$ pesos en comparación de lo que paga un nacional 200 a 300 pesos $^{5}$, los empleadores extranjeros hacen caso omiso a la obligatoriedad de la inscripción a la seguridad social, al igual que sus pares nacionales.

Para tratar de frenar esta situación y en vista de la buena comunicación que tienen entre sí las trabajadoras del hogar mazatecas en Puebla, desde finales de marzo de 2020, a través de redes sociales, conversaciones telefónicas y visitas personales generaron un seguimiento de las condiciones de sus vecinas, comadres y paisanas. Ante el desentendimiento estatal y de los empleadores, familiares, amigos y trabajadoras del hogar mazatecas organizaron la campaña "Una mano para las trabajadoras mazatecas", que se extendió hasta finales de octubre de 2020. La campaña acompañó con despensas de comida y de productos de aseo, para las mujeres más afectadas, es decir, aquellas que no contaban con ninguna salida laboral, eran de edad avanzada y madres solteras.

Es gracias al escenario de politicidad doméstica histórica que las trabajadoras han construido desde su niñez que fue posible el desarrollo exitoso de la campaña ${ }^{6}$. Lupita y su sobrina se han encargado de estar pendientes de otras mujeres, colegas de trabajo, paisanas y comadres, afectadas por la pandemia.

Los hijos e hijas de las trabajadoras mejor posicionadas dieron difusión de la campaña en redes sociales, contactaron a amigas, amigos y profesores, diseñaron los afiches, elaboraron videos, dispusieron una cuenta bancaria para recoger los aportes, dieron entrevistas en medios de comunicación locales y se encargaron de llevar las cuentas. Otro grupo, realizó las compras y buscó ofertas más económicas a pesar de la pandemia. Lupita y su sobrina se encargaron de comunicar a las trabajadoras cuando las despensas estaban

20 a 25 dólares.

10 a 15 dólares.

6 Para conocer más sobre la campaña "Una mano para las trabajadoras del hogar”, remitirse a: https://www.facebook.com/watch/?v=220193566044680 
listas, de coordinar para su entrega, de escoger el mejor modo de distribución según las necesidades de sus allegadas.

Durante el confinamiento también se activó la red para apoyar a mujeres que se quedaron sin casa por no poder pagar la renta, algunas fueron a vivir con otras mujeres con casa propia, otras regresaron a San Lorenzo Cuaunecuiltitla a vivir con familiares, o a casas que construyeron con su trabajo en la ciudad.

Del mismo modo, se activaron diferentes formas de cooperación, para mitigar gastos que varias familias tuvieron por las muertes de familiares.

Cuando murió el hermano de mi comadre, entre paisanos cooperamos. Estuvo la familia pidiendo apoyo para llevarlo al pueblo o enterrarlo acá, lo que hicieron fue una cooperación. En mazateco se dice kotjú —favor. Cuando alguien muere acá todos se reúnen, cooperan. Apoyamos porque cuando a ti te pasa algo, todo mundo te apoya, no te dejan solo (Lupita G., trabajadora del hogar, 2021).

La politicidad doméstica en momentos de desempleo, muertes, desalojos, pandemia, nos demuestra cómo se generan formas creativas de redistribución de recursos. Desde la realización de tandas, préstamos, apoyo a paisanos con necesidades, acogimiento de paisanas o niños que han vivido violencias, estas redes constituyen formas de hacer política en el espacio íntimo. Lo personal es político, y más en tiempos de COVID-19. El día a día es resistencia colectiva y, por ende, se constituye como política doméstica.

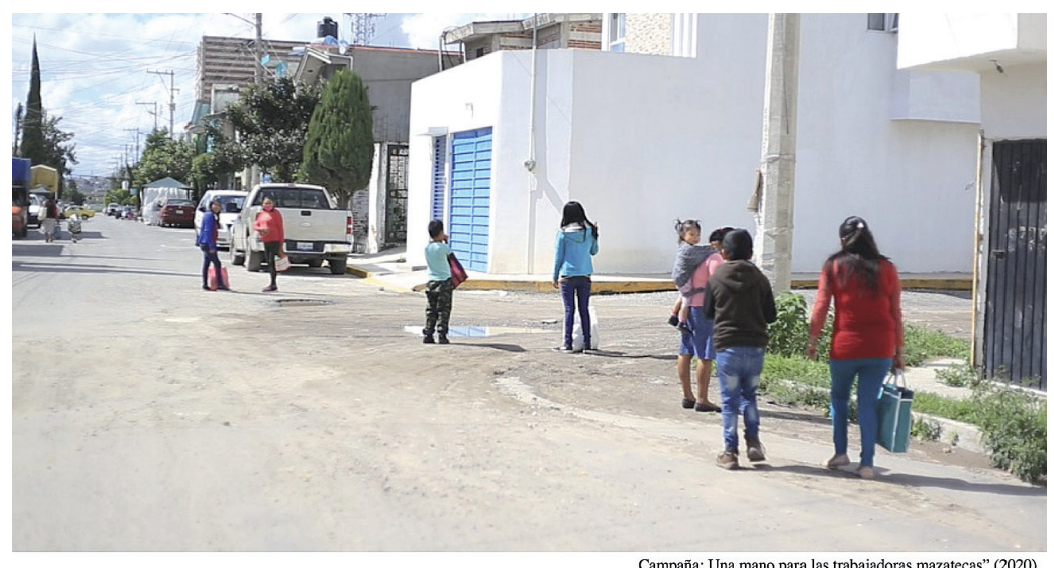

Campaña: Una mano para las trabajadoras mazatecas" (2020) Nueva San Salvador, Puebla 


\section{CONCLUSIONES}

Históricamente, en la Sierra Mazateca de México, el trabajo de mujeres y niñas ha sido un recurso "natural" disponible para la reproducción física, emocional e identitaria de sociedades profundamente jerárquicas y racialmente estructuradas. Las condiciones de explotación en el trabajo, no se modificaron sustantivamente con la migración a las grandes ciudades como Puebla, lo que revela una mixtura altamente ambigua entre el mundo laboral, la servidumbre y la familiaridad. El trabajo del hogar continúa estando en manos de niñas, jóvenes y mujeres, reproduciéndose de este modo regímenes de género desiguales que dotan de contemporaneidad a las jerarquías raciales, de género y clase características del legado de la colonia y del período republicano.

Esa estructuración históricamente jerarquizada y desigual es lo que configura (y necesita) el actual modo de acumulación capitalista para su funcionamiento. En él, los conflictos económicos, raciales y sexuales tienen modos de expresión diversos, y generalmente, lo hacen con violencia sobre los cuerpos de mujeres trabajadoras.

A pesar de las contradicciones, conflictividades y la carga desigual que las mujeres llevan en la producción de lo común (Vega et al., 2018), las trabajadoras producen y reproducen prácticas que tienden a enfrentar las dificultades. Permanentemente, y aún más en contextos de radicalización de crisis, las organizaciones colectivas y comunitarias, en la mayoría de los casos construidas por mujeres, tienden a profundizar sus vínculos y a sostener con más fuerza a sus miembros. Como mencionamos, tales formas organizativas, no siempre son visibles, porque escapan a las lógicas tradicionales e institucionales de organizaciones indígenas o sindicales. Constituyen dinámicas complejas que van desde modalidades de cooperación, reciprocidad y cuidados, hasta fuertes conflictos y prácticas de dominación, en negociación permanente. En este sentido, al centrar la reproducción social como fundamento de la vida, se valoran las experiencias de organización y defensa de lo común que grupos de mujeres han desplegado en diferentes partes del continente. No se trata de romantizar las condiciones de desigualdad o las vulneraciones que estas mujeres han vivido de manera histórica, sino reconstruir una apuesta ético-política de visibilización y reconocimiento de estas formas de organización colectiva en torno al trabajo, que sostienen la vida social con toda su complejidad, y que generalmente son olvidadas por las formas hegemónicas de hacer política. 
En el caso de las mujeres mazatecas, desde mitad del siglo XX, en el marco de la caída internacional del precio del café, producto vertebrador de la economía regional, comenzaron procesos de migración hacia las grandes ciudades. Estas mujeres eran llevadas por una madrina que le conseguía trabajo en casas de familia. Actualmente, son esas "viejas generaciones", que, a través de la red de paisanaje o compadrazgo, asisten, dan hospedaje y comida, a las mujeres que van llegando a la ciudad en busca de trabajo. Estas primeras generaciones, en algunos casos, acumularon capital simbólico como mediadoras de estas redes e intercambios. El trabajo doméstico remunerado, sin embargo, históricamente se ha caracterizado por ser un sector de desprotección y violencia para las trabajadoras, que aún en la actualidad manifiesta escasa o nula afiliación a la seguridad social. Sin embargo, es preciso destacar que las mujeres que llegaron a Puebla entre los años 60 y los 80 del siglo pasado, han podido acceder a la propiedad de la tierra donde hoy tienen sus viviendas producto de estas redes de apoyo y organización.

Como pusimos en evidencia en el artículo, no se trata de una organización institucionalmente establecida, sino de una amplia red de solidaridad que llevan adelante múltiples actividades cotidianas en torno al trabajo de sostener la vida en comunidad, y que se mantiene gracias al aporte de dones y contra dones de sus miembros. Por lo general, no son redes basadas en el contacto individual, sino en relaciones colectivas, en las que las familias sanguíneas forman parte de redes de parentesco ritual ampliado como el madrinazgo y el compadrazgo.

Analizar la politicidad en torno al trabajo nos permitió, por un lado, romper con la separación entre público y privado, entre lo productivo y reproductivo, al contemplar formas de intercambio, a veces de trabajo, a veces de productos, en términos individuales, aunque generalmente colectivos, asentados centralmente en las mujeres de diversas generaciones. Como vimos, la crisis suscitada por el COVID-19 no sólo mostró la agudización de las condiciones de precariedad de la vida en que las trabajadoras del hogar, remuneradas o no, despliegan su cotidianidad, sino también ha generado experiencias constitutivas en las que la protección de la vida se vuelve el centro. A pesar de los conflictos, las trabajadoras producen y reproducen prácticas políticas que tienden a enfrentar las dificultades, creando fuertes vínculos entre ellas y redes de cuidado que actualizan conformando una politicidad doméstica, que trasciende territorios y temporalidades. 


\section{BIBLIOGRAFÍA}

Arteta, I. (2021, febrero 10). Pese a pandemia y a ser voluntaria, afiliación de trabajadoras del hogar al IMSS subió. Animal Político. Recuperado de https:/www.animalpolitico.com/2021/02/afiliacion-trabajadoras-delhogar-imss-pandemia/

Berg, U. D., \& Ramos-Zayas, A. Y. (2017). La racialización del afecto: una propuesta teórica”, en Etnografías Contemporáneas, Año 3, No 5, pp. 216 276.

Carrasco, C. (2017). La economía feminista. Un recorrido a través del concepto de reproducción. Ekonomiaz: Revista vasca de economía, 91. Recuperado de https://dialnet.unirioja.es/servlet/articulo?codigo $=6038693$

Chirix, E. (2012). Dos generaciones de mujeres mayas: Disciplinas corporales en el internado Instituto Indígena Nuestra Señora del Socorro. (Tesis inédita de doctorado). Guadalajara: CIESAS.

Consejo para prevenir y eliminar la discriminación de la Ciudad de México (COPRED) (2021). Informe sobre la situación de los derechos de las personas trabajadoras del hogar en la Ciudad de México. Ciudad de México: COPRED.

Cumes, A. (2014). La "india" como "sirvienta": Servidumbre doméstica, colonialismo y patriarcado en Guatemala. (Tesis inédita de doctorado). México D.F.: CIESAS.

Dalla Costa, M., \& James, S. (1972). El poder de la mujer y la subversión de la comunidad. México: Siglo XXI.

Durin, S. (2017). Yo trabajo en casa Trabajo del hogar de planta, género y etnicidad en Monterrey. México: CIESAS.

Federici, S. (2016). Calibán y la bruja. Mujeres, cuerpo y acumulación originaria. Quito: Ediciones Abya-Yala.

Gago, V., Cielo, C., \& Gachet, F. (2018). Presentación del dossier. Economía popular: Entre la informalidad y la reproducción ampliada. Íconos - Revista de Ciencias Sociales, (62), 11-20. (1997-). doi: 10.17141/ iconos.62.2018.3501

Gutiérrez, R. (2017). Políticas en femenino: Transformaciones y subversiones no centradas en el estado. En Horizontes comunitario-populares Producción de lo común más allá de las políticas estado-céntricas. Madrid: Traficantes de Sueños.

Gutiérrez, R., \& Salazar, H.r (2015). Reproducción comunitaria de la vida Pensando la transformación social en el presente. el Apantle. Revista de estudios comunitarios, 1, 15-50.

Harvey, D. (2006). Acumulación por desposesión. En Espacios globales (C. Bueno, M. Negrete, S. Alarcón, pp. 21-52). México D.F: Universidad Iberoamericana.

Morales, A. (2019). El impacto de la herencia patriarcal de la hacienda en la vida de las mujeres afroecuatorianas en la sierra norte ecuatoriana. Revista Andina de Estudios Políticos, 9(2), 80-93. doi: 10.35004/raep.v9i2.153 
Nahuelpán, H.r (2013). Las 'zonas grises'de las historias Mapuche. Colonialismo internalizado, marginalidad y políticas de La memoria. Revista de Historia Social y de las Mentalidades, 17(1), 11-34.Recuperado de http://www.revistas.usach.cl/ojs/index.php/historiasocial/article/view/ $1552 / 1429$

Navarro, M. (2019). Despojo múltiple sobre el tejido de la vida: Impactos y resistencias sociambientales. Section: Social movements and rural culture doi: 10.5154/r.textual.2018.73.01

Oehmichen-Bazán, C. (2013). Apuntes para una etnografía entre los migrantes en las ciudades. Cahier, 2013-02.

Orozco Pérez, A. (2021). S ubversión feminista de la economía laportes para un debate sobre el conflicto capital-vida. Recuperado de https://www.traficantes. net/libros/subversi\%C3\%B3n-feminista-de-la-econom\%C3\%ADa

Patiño, E. (2004). Periferia poblana: La desigualdad del crecimiento. Papeles de Población, 10(42), 0. Recuperado de https://www.redalyc.org/articulo. oa? id=11204206

Quijano, A. (2000). Colonialidad del poder y Clasificación Social. Journal of World Systems research, VI, 342-386.

Quiroga, N., \& Gago, V. (2017). Una mirada feminista de la economía urbana y los comunes en la reinvención de la ciudad. En C. Carrasco \& C. Díaz (Eds.), Economía feminista: Desafíos, propuestas. Barcelona: Entrepueblos.

Tzul, G. (2018). Sistemas de gobierno comunal indígena: la organización de la reproducción de la vida. En M. P. Meneses \& K. Bidaseca (Eds.), Epistemologías del Sur, CLACSO, 385-396. doi: 10.2307/j. ctvtxw2km.7

Varela, A. (2017). La trinidad perversa de la que huyen las fugitivas centroamericanas: Violencia feminicida, violencia de estado y violencia de mercado. Debate Feminista (53), 1-17. doi: 10.1016/j.df.2017.02.002

Vega, C., Marega, M., \& Salzmann, L. (2019). Protagonismo femenino y construcción de la ocupación. La apropiación del espacio urbano por parte de las vendedoras minoristas en la Martha Bucaram (Quito, Ecuador). En Trabajos y trabajadores en América Latina (siglos XVIXXI) (Vicepresidencia del Estado Plurinacional de Bolivia, Centro de Investigaciones Sociales (CIS), pp. 537-574). La Paz.

Vega, C., Martínez, R., \& Paredes, M. (Eds.) (2018). Cuidado, comunidad y común. Experiencias cooperativas en el sostenimiento de la vida. Madrid: Traficantes de Sueños.

Vera, C., \& Vega, C. (2020). Trabajo, género y servidumbre. La entrega de niñas indígenas para el trabajo del hogar. En H. Palermo \& L. Campogrossi (Eds.), Tratado latinoamericano de Antropología del Trabajo (1era Edición). Buenos Aires: CLACSO.

Velázquez, B. (2012). Los programas sociales en México como sustento de la economía social y solidaria. México: Instituto Belisario Domínguez del Senado de la República.

Young, G. (1987). The Myth of Being «Like a Daughter». Latin American Perspectives, 14 (3), 365-380. 